\title{
A Compact Ultra-Wide Band Rhombus Shaped Fractal Antenna With Metamaterial In the Ground Plane

\author{
Ch.Manohar Kumar, NVSS Kumar Muvvala
}

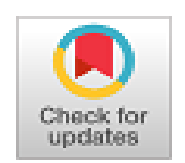

\begin{abstract}
An ultra wide band pattern antenna with rhombus fractal geometry has been proposed in this paper. In order to enhance the gain and directivity of the antenna, Meta material iss placed in the ground plane. The effect of the meta material on the overall performance of the rhombic patch is also presented in this paper. The design and analysis of the proposed fractal antenna is carried by using CST Microwave Studio 2015 and MATLAB $R 2014 b$. The measured antenna characteristics such as gain and directivity of the proposed antennas are found well matched to the simulated results.
\end{abstract}

Index Terms: Directivity, Fractal Geometry, Gain, Multi-band, Sierpinski carpet

\section{INTRODUCTION}

Antenna with compact size and multiband application plays a crucial role in the present modern telecommunication system. To achieve more data transmission capability at very lower level power, lower cost, alleviate in fabrication etc., with simple compact wide band antenna is more difficult. But certain extent these needs can be fulfilled with the help of fractals in ultra wideband (UWB) antenna design [1]. Fractal geometry is the most popular as it has exceptional properties for improving the characteristics of patch antennas. Primarily the fractal geometry is employed to attain the multiband characteristics and it is not possible with the conventional microstrip patch (MSP) antenna. The nature of structure is complex in the case of fractal shapes and they can be created with the help of recursive procedures which shows more surface area in limited amount of space [2]. The unique properties of fractals are self-similarity and space-filling. These properties enable the realization of antennas with multi-band operation and miniaturization. The self-similarity offers multiband properties and space-filling property makes the antenna miniaturized. Therefore, a compact and wide band antenna can be designed with the use of fractal geometries. A large variety of designs regarding fractal antenna were reported in the literature. While designing antenna, various fractal geometry shapes and forms may be considered. Puente et al. investigated the multiband manner of a fractal Sierpinski antenna [3]. Subsequently more developments made in this direction. As there is a rapid growth of mobile systems towards fifth-generation, several attempts made on developing UWB antennas using fractal geometries.

\section{Revised Manuscript Received on October 30, 2019.}

* Correspondence Author

Ch.Manohar Kumar*, Research Scholar, School of Engineering \& Technology, Career point University, KOTA, Rajasthan, India.

NVSS Kumar Muvvala, Research Supervisor, School of Engineering \& Technology, Career point University, KOTA, Rajasthan, India.

(C) The Authors. Published by Blue Eyes Intelligence Engineering and Sciences Publication (BEIESP). This is an open access article under the CC BY-NC-ND license (http://creativecommons.org/licenses/by-nc-nd/4.0/)
Behera et al. adopted Koch iteration technique to develop antenna suitable for ultrawideband communication applications. They inserted Sierpinski carpet into the triangular shaped patch as a slot. They observed that their proposed antenna exhibits an improvement in terms of S-parameters and band width [4]. Dieu and Zhou proposed circular fractal antenna with UWB and simulation study has been carried for observing the characteristics using CST MWS 2012[5]. Singhal et al. designed an asymmetrical CPW-fed octagonal shaped fractal antenna for UWB purposes [6]. Tripathi et al. made an attempt to fabricate the prototype of fractal UWB antenna with compact octagonal shape with the use of Sierpinski fractal geometry. They concluded that their proposed antenna provides nearly omnidirectional radiation pattern, good return loss with good time domain response in terms of fidelity factor over the entire UWB frequency range [7]. Kaka and Toycan [8] proposed hexagonal Sierpinski gasket antenna through considering the characteristics such as space-filling and self-similarity. Mishra and Sahu [9] designed a compact modified dual band notched UWB antenna with octahedron configuration. They concluded that the antenna achieved the wide impedance bandwidth. Kumar and Kushwaha [10] made an attempt to design sectoral circular disc fractal antenna. On comparing with the outcome of the simulation study, they stated that there calculated characteristics values are closer to the results of simulation.Even though with the use of dielectric substrate having good permittivity and using shorting wall, shorting pins, fractal geometry etc. for miniaturization of antenna, it also suffers with narrow band width and low gain. To address this issue various designers suggested the application of metamaterials for antenna design. The use of metamaterials leads to reducing the size of the antenna and also enhances band width and increases gain. The characteristics of metamaterials are negative permittivity or permeability or both may be negative at the same time. These are the composites of macroscopic cells of periodic / non-periodic structures, whose function is influenced by the architecture of the cells and chemical composition [11]. The one or more metamaterials are used as substrates for preparing metamaterials antennas. In antenna design the metamaterials can be applied in the form of a unit cell or multiple unit cells assembled together into an array [12]. The design of unit cells of metamaterials has been carried on the basis of the calculation of size and simulation of unit cells and in accordance with the satisfaction of permittivity and permeability to the expected resonant frequency. It is usually obtain different values of permittivity, permeability and resonant frequency against the structure and size of each unit cell [13]. 
A remarkable progress of using metamaterials in improving the design parameters of antenna is observed in the literature. Han et al. [14] proposed a compact UWB microstrip antenna provided with metamaterials. They achieved an average gain of $6.2 \mathrm{~dB}$, which is $1.2 \mathrm{~dB}$ larger than the original patch antenna. Lou et al. [15] employed two types of metamaterial superstrates with a view to increase directivity, gain and bandwidth. They used Ansoft HFSS for simulation and results indicate that the gain, directivity and bandwidth of the antenna with metamaterial superstrate are increased at Ku-band (13-17GHz). Bimal Garg, et al. [16] proposed microstrip patch antenna with pentagonal rings shaped metamaterial cover and analyzed at a height of $3.2 \mathrm{~mm}$ from the ground plane. They noticed that the proposed metamaterial cover significantly reduces the return loss and increases the directivity of the antenna in comparison to rectangular microstrip patch antenna alone.

This paper deals with a compact UWB rhombic patch antenna with metamaterials in the ground plane so as to observe the improvement in gain and directivity. The rest of the paper is organized as follows. The proposed antenna design is presented in Section II. The Section III describes the simulation results and comparison of conventional antenna and the proposed antenna. Finally the Section IV presents the conclusions of the work.

\section{ANTENNA DESIGN}

The proposed antenna has six unit cells of the metamaterial which form a $3 \times 2$ matrix of metamaterial beneath the substrate. Usually the fractal design has two components namely initiator and generator. The initiator ( $0^{\text {th }}$ stage) contains the basic shape of the geometry. In generator the shape which gets repeated in a pattern in subsequent stages with different dimensions. In the proposed design, the rhombus has been chosen as base or initiator shape. The side of the rhombus is $30 \mathrm{~mm}$. The figure 1 depicts the basic geometry of the initiator for the proposed antenna.

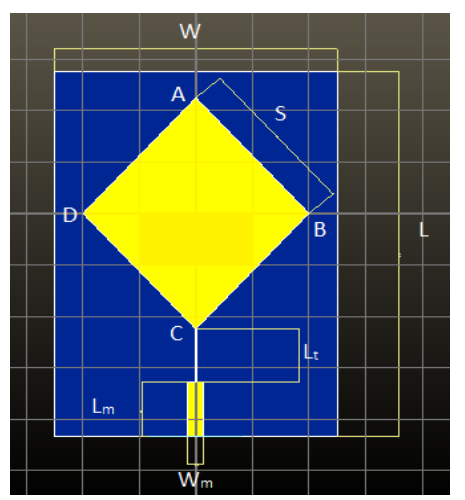

Fig.1. Geometry of the initiator $\left(0^{\text {th }}\right.$ stage $)$

It is printed on an FR-4 dielectric substrate, whose thickness is $1.6 \mathrm{~mm}$ and dielectric constant is 4.4 . The substrate is laid on a rectangular ground plane whose length and width are $L$ and $W$ respectively. The feed that the proposed antenna uses is the quarter wave transformer feed fed at the geometric centre of the radiating rhombic patch aimed to achieve a satisfactory impedance matching.

Design parameters:

Side of the rhombus $(S)=30 \mathrm{~mm}$
Length of the substrate $(L)=70.8 \mathrm{~mm}$

Width of the substrate $(W)=58 \mathrm{~mm}$

Length of the quarter wave transmission line $\left(L_{\mathrm{t}}\right)=10 \mathrm{~mm}$

Length of the micro strip line $\left(L_{\mathrm{m}}\right)=10 \mathrm{~mm}$

Width of the microstrip line $\left(W_{\mathrm{m}}\right)=2.78 \mathrm{~mm}$

The proposed antenna is simulated and optimized using CST Microwave studio 2015 and MATLAB R2014b.

\section{SIMULATION RESULTS AND DISCUSSION}

In this work simulation of rhombus shape fractal antenna up to $3^{\text {rd }}$ iteration has been carried in terms of return loss, voltage standing wave ratio (VSWR), gain and directivity at frequencies range from $5.2 \mathrm{GHz}$ to $20 \mathrm{GHz}$ using CST MWS 2015. The process of removing some parts of basic structure leads to miniaturization of the fractal structure in each iteration. The results for different iteration are discussed below.

\section{Iteration 0:}

The figure 2(a) represents the variation of return loss with frequency. From the figure 2(a), it is observed that the reflection coefficient is negative (less than $-15 \mathrm{~dB}$ ) at the desired frequencies. Figure 2(b) shows a plot drawn between VSWR and frequency for the S-parameters obtained.

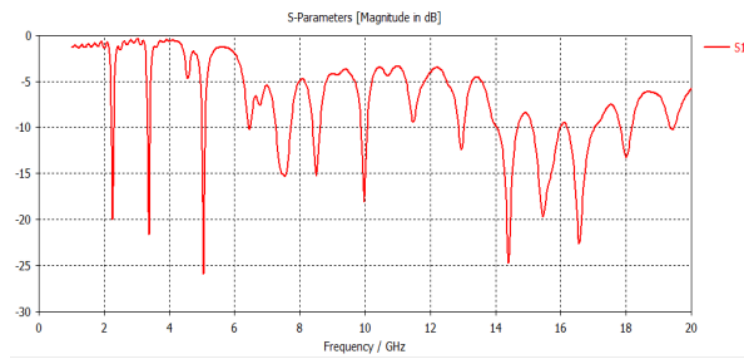

(a)

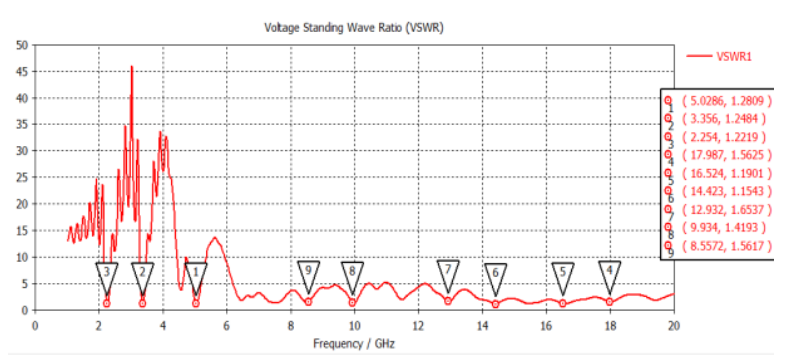

(b)

\section{Fig.2 (a) Return loss vs frequency (b) VSWR vs frequency}

The VSWR of the base shape is nearly equal to one for most of the frequencies under consideration.

\section{Iteration 1:s}

The construction of the sierpinski carpet begins with dividing the side $(A B)$ of the rhombus into three equal parts and then the three line segments join the corresponding ones of the opposite side $(C D)$ of the rhombus. The same procedure is adopted for the sides $B C$ and $A D$ also. Finally nine congruent rhombuses are formed and the central rhombus is removed. 
The resulting iterated rhombic patch is shown in figure 3(a). The total area of the base shape (rhombus) is $900 \mathrm{~mm}^{2}$ and the area of the removed rhombus is equal to one-ninth of the total area. The remaining area will be $800 \mathrm{~mm}^{2}$. Therefore the effective area of the patch is reduced by $100 \mathrm{~mm}^{2}$. The simulated return loss characteristics and VSWR are shown in figure 3(b) and 3(c) respectively.

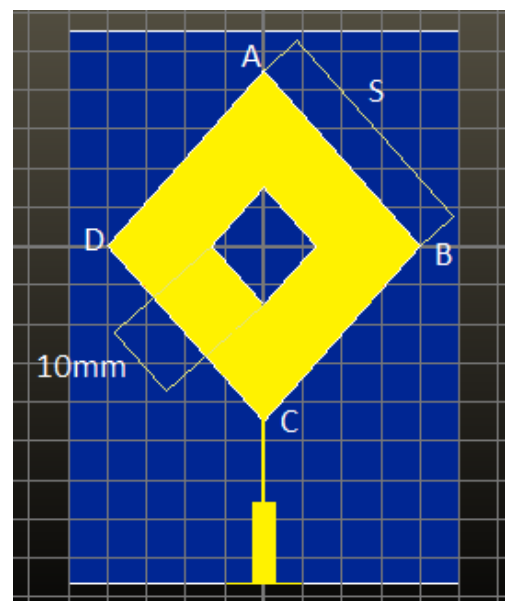

(a)

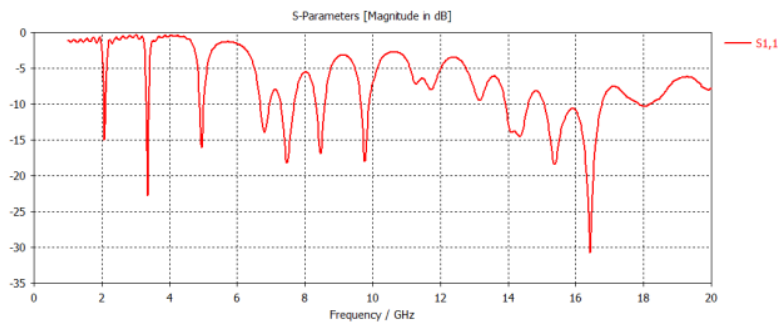

(b)

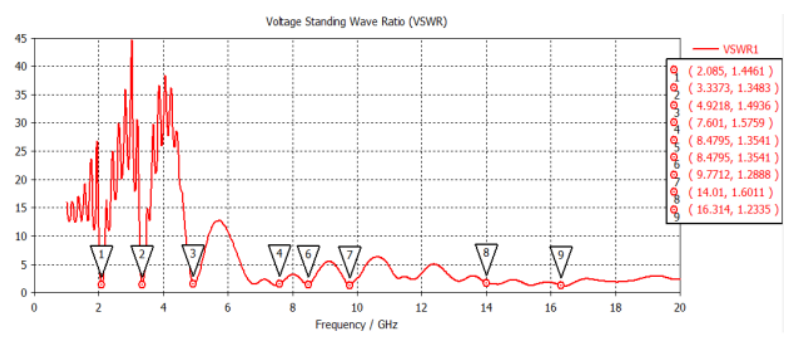

(c)

Fig.3 (a) Iterated rhombic patch (b) Return loss vs frequency (c) VSWR vs frequency.

\section{Iteration 2:}

The iterated rhombic patch shown in figure 4(a) is obtained through the procedure same as that applied in the first iteration. The area of the singly iterated patch is $800 \mathrm{~mm}^{2}$. The area of the doubly iterated patch will be computed as follows.

Area of the doubly iterated patch $=$ $800-4\left[\frac{1}{9}\left(\frac{1}{9} \times 900\right)\right]=755.56 \mathrm{~mm}^{2}$.

The effective area of the patch is reduced by $44.44 \mathrm{~mm}^{2}$. The simulated return loss characteristics and VSWR are shown in figure 4(b) and 4(c) respectively.

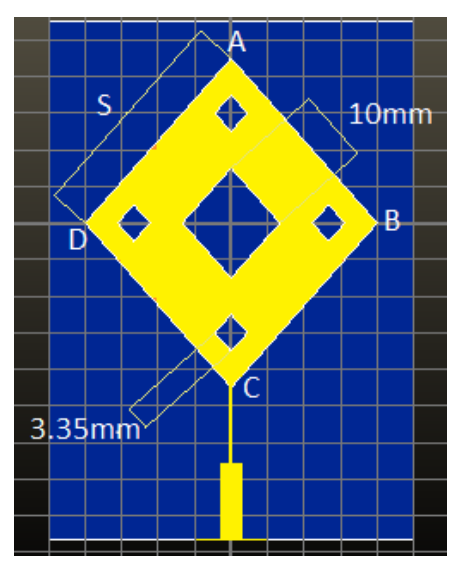

(a)

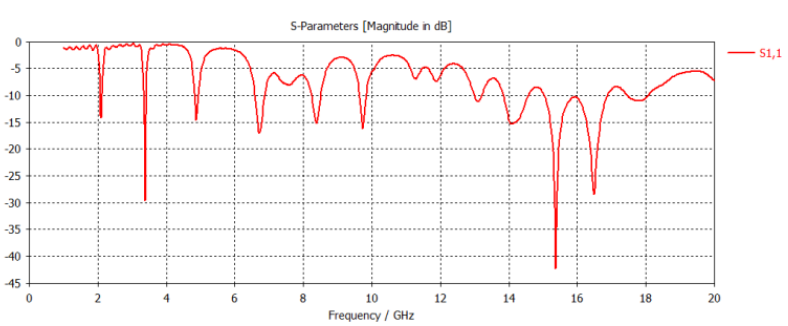

(b)

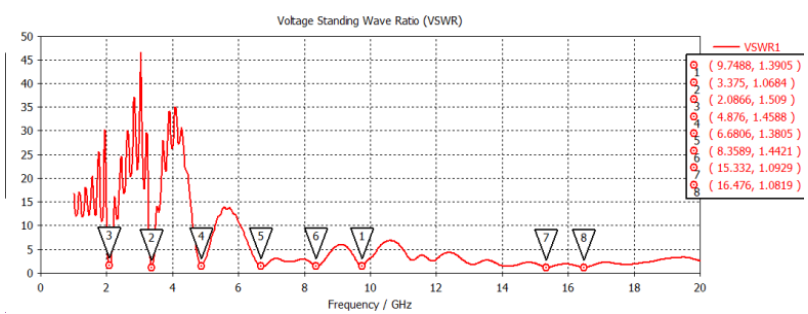

(c)

Fig.4 (a) Iterated rhombic patch (b) Return loss vs frequency (c) VSWR vs frequency

\section{Iteration 3:}

The figure 5(a) shows the iterated rhombic patch which is obtained by the procedure same as adopted in the earlier iterations. The enlarged view is also presented in the figure 5(a). The area of the doubly iterated patch is $755.56 \mathrm{~mm}^{2}$. The area of the triply iterated patch will be computed as follows.

Area of the triply iterated patch $=$ $755.56-16\left\{\frac{1}{9}\left[\frac{1}{9}\left(\frac{1}{9} \times 900\right)\right]\right\}=735.8 \mathrm{~mm}^{2}$.

The effective area of the patch is reduced by $19.753 \mathrm{~mm}^{2}$. The simulated return loss characteristics and VSWR are shown in figure 5(b) and 5(c) respectively. 

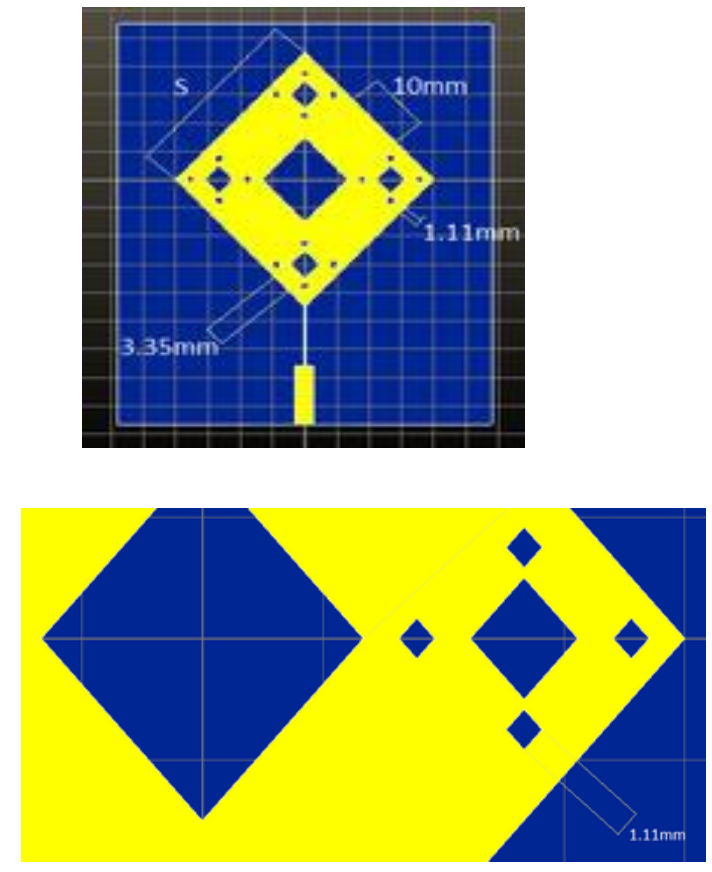

(a)

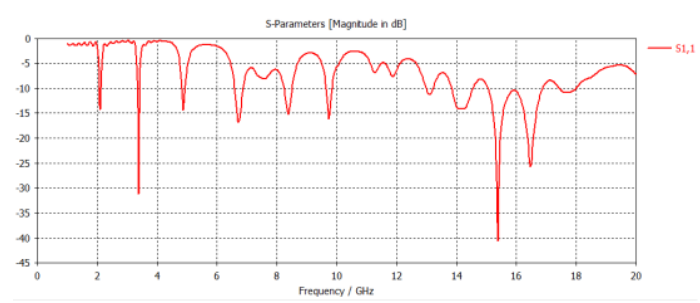

(b)

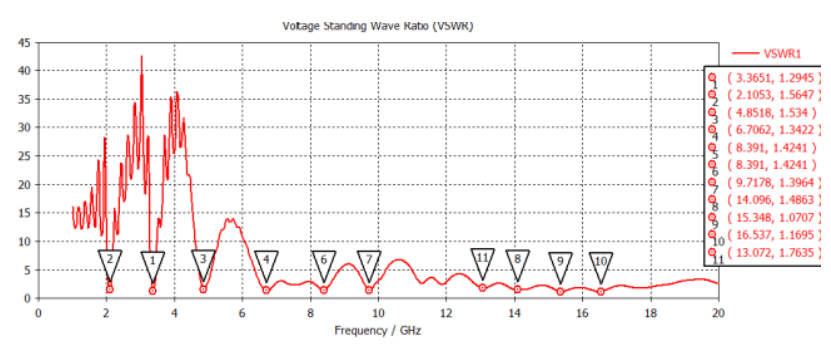

(c)

Fig.5 (a) Iterated rhombic patch and its enlarged view $\begin{array}{lll}\text { (b) Return loss vs frequency } & \text { (c) VSWR vs }\end{array}$ frequency.

Metamaterial is applied in the form of unit cell and its design involves a semi-circular strip riveted in between two rectangular strips on the either side of it along the diameter as shown in figure 6. The complete dimensions are also represented in the figure 6 . The graphs are drawn for the properties of unit cell such as permeability, permittivity against frequency are shown in figure 7. The real and imaginary refractive index and impedance against frequency are shown in figure 8 and figure 9 respectively.

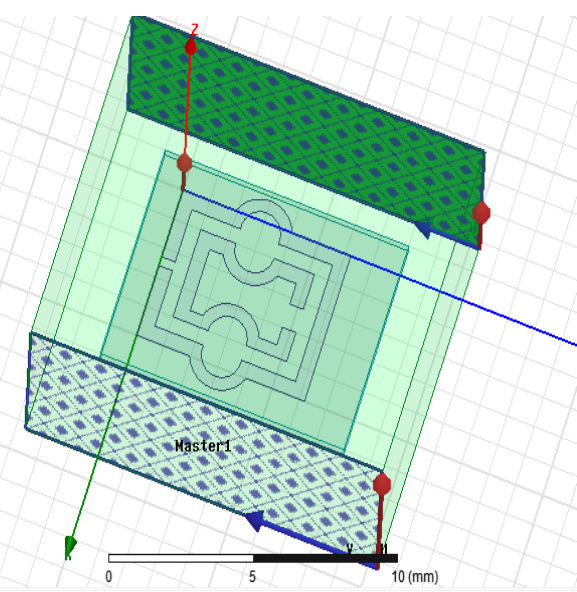

Fig.6. Unit cell of the proposed metamaterial

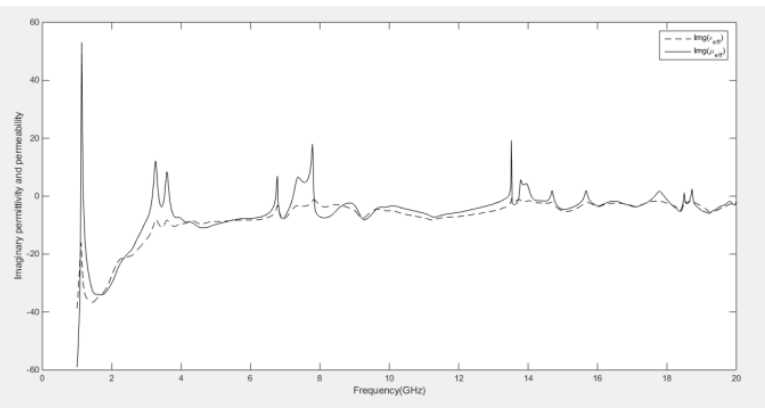

Fig.7. Imaginary permittivity and permeability vs frequency

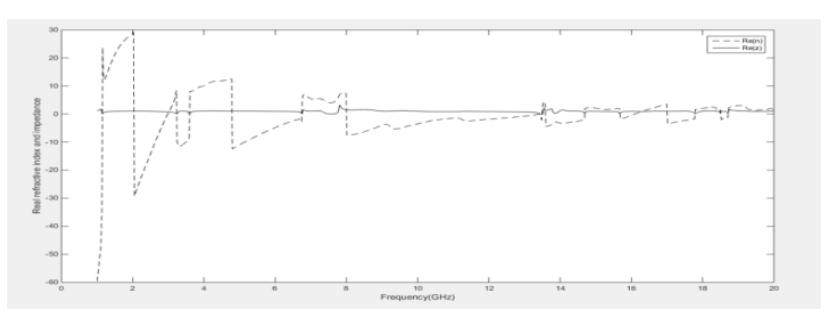

Fig.8. Real refractive index and Impedance vs frequency

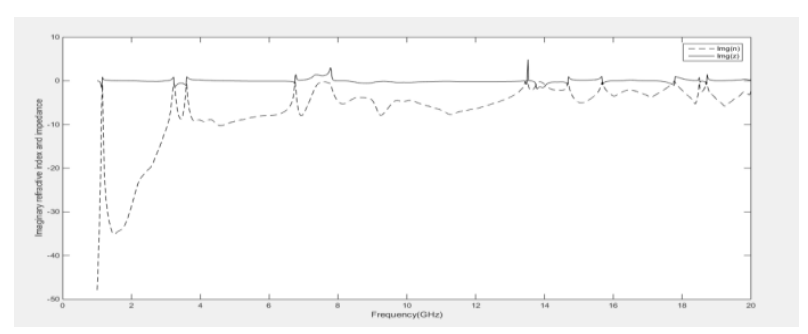

Fig.9. Imaginary refractive index and Impedance vs frequency

The following expressions relating permittivity $(\varepsilon)$ and permeability $(\mu)$ to $S$-parameters are considered.

Reflection co-efficient $\left(S_{11}\right)=\frac{R_{01}\left(1-e^{i 2 n k_{0} d}\right)}{1-R_{01}^{2} e^{i 2 n k_{0} d}}$ 
Transmission co-efficient $\left(S_{21}\right)=\frac{\left(1-R_{01}^{2}\right) e^{i 2 n k_{0} d}}{1-R_{01}^{2} e^{i 2 n k_{0} d}}$

$e^{i 2 n k_{0} d}=\frac{S_{21}}{1-S_{11}\left(\frac{z-1}{z+1}\right)}$

$n=\frac{1}{k_{0} d}\left[\left\{\left[\ln \left(e^{i n k_{0} d}\right)\right]^{\prime \prime}+2 m \pi\right\}-i\left[\ln \left(e^{i n k_{0} d}\right)\right]^{\prime}\right]$

$Z= \pm \sqrt{\frac{\left(1+S_{11}^{2}\right)-S^{2}}{\left(1-S_{11}\right)^{2}-S^{2}}}$

Where, $R_{01}=\frac{z-1}{Z+1}$

$k_{0}=$ Wave number

$z=$ Impedance

$d=$ Maximum length of the unit element

$n=$ Refractive index

$m=$ Branch due to the periodicity of the sinusoidal function

The permittivity and permeability are related to the refractive index and impedance by the following expressions:

$\mu=n z$

$\varepsilon=\frac{n}{Z}$

The permittivity and permeability of the unit cell can be calculated using the above formulae which are numerically computed using MATLAB R2014b.

\section{Proposed antenna:}

The proposed antenna has six unit cells of the metamaterials which form a $3 \times 2$ matrix of metamaterial beneath the substrate and it is shown in figure 10.

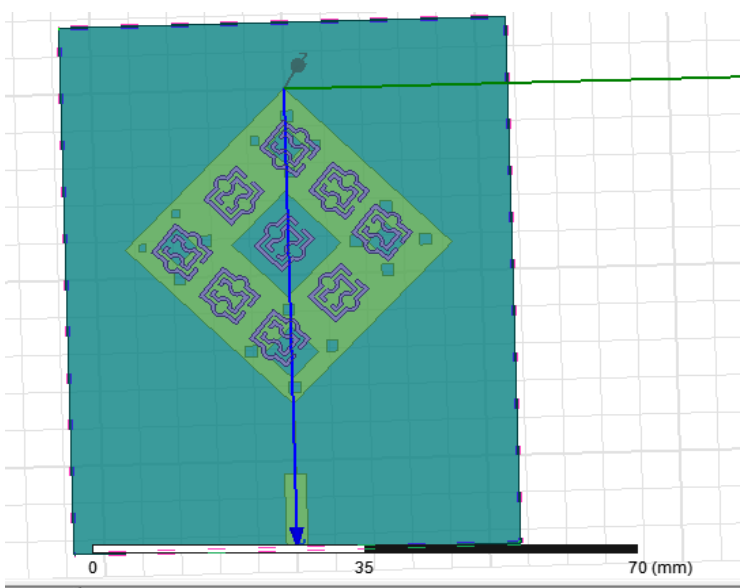

Fig.10. Proposed rhombus shaped antenna with meta material

The effect of this metamaterial layer on the overall performance of the triply iterated rhombic patch is illustrated in terms of S11 and VSWR and is shown in figure 11 and figure 12 respectively.

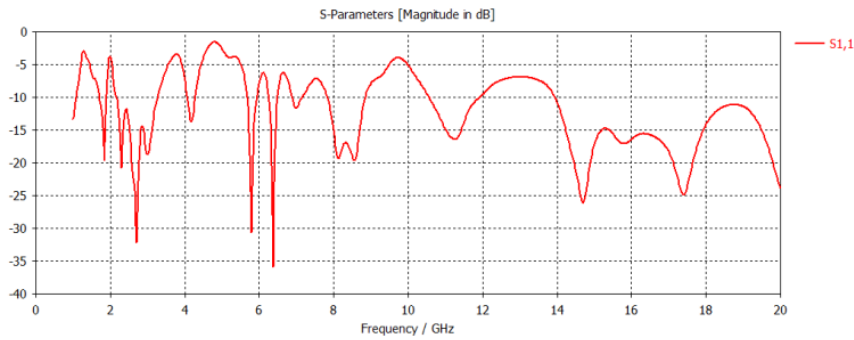

Fig. 11. Return loss vs frequency

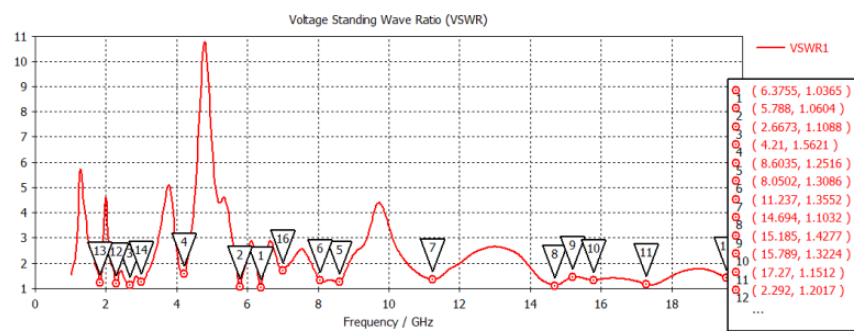

Fig. 12. VSWR vs frequency

The gain and directivity obtained in each iteration are summarized in the table 1.

Table 1. Gain and directivity in each iteration

\begin{tabular}{|c|c|c|c|c|c|c|}
\hline Parameter & \multicolumn{7}{|c|}{ Zeroth iteration } \\
\hline $\begin{array}{c}\text { Frequency } \\
\text { (GHz) }\end{array}$ & 5.2 & 10.5 & 12.5 & 16.2 & 17.5 & 20 \\
\hline $\begin{array}{c}\text { Gain } \\
\text { (dB) }\end{array}$ & 0.522 & 2.432 & 2.414 & 0.02 & 2.914 & 1.69 \\
\hline $\begin{array}{c}\text { Directivity } \\
\text { (dB) }\end{array}$ & 7.395 & 11.9 & 10.39 & 6.954 & 9.719 & 8.567 \\
\hline Parameter & \multicolumn{7}{|c|}{ First iteration } \\
\hline $\begin{array}{c}\text { Frequency } \\
\text { (GHz) }\end{array}$ & 5.2 & 10.5 & 12.5 & 16.2 & 17.5 & 20 \\
\hline $\begin{array}{c}\text { Gain } \\
\text { (dB) }\end{array}$ & 0.8126 & 1.23 & 2.724 & 1.486 & 2.621 & 1.946 \\
\hline $\begin{array}{c}\text { Directivity } \\
\text { (dB) }\end{array}$ & 6.29 & 9.84 & 8.346 & 8.921 & 9.72 & 10.21 \\
\hline Parameter & \multicolumn{7}{|c|}{ Second iteration } \\
\hline $\begin{array}{c}\text { Frequency } \\
\text { (GHz) }\end{array}$ & 5.2 & 10.5 & 12.5 & 16.2 & 17.5 & 20 \\
\hline $\begin{array}{c}\text { Gain } \\
\text { (dB) }\end{array}$ & 1.212 & 0.7857 & 2.679 & 3.164 & 3.186 & 2.281 \\
\hline $\begin{array}{c}\text { Directivity } \\
\text { (dB) }\end{array}$ & 5.74 & 9.943 & 8.757 & 8.734 & 8.701 & 8.490 \\
\hline Parameter & & 6.2 & 5.3 & 8.1 & 5.6 & 6.638 \\
\hline $\begin{array}{c}\text { Frequency } \\
\text { (GHz) }\end{array}$ & 5.2 & 10.5 & 12.5 & 16.2 & 17.5 & 20 \\
\hline $\begin{array}{c}\text { Gain } \\
\text { (dB) }\end{array}$ & 2.086 & 1.067 & 3.184 & 6.945 & 4.73 & 3.133 \\
\hline $\begin{array}{c}\text { Directivity } \\
(\mathrm{dB})\end{array}$ & 4.6 & 6.2 \\
\hline
\end{tabular}

The gain and directivity values for the frequency range considered are shown in table 2. From the tables 1 and 2, it is observed that in the case of proposed antenna there is a considerable increase in gain and directivity. 


\section{CONCLUSIONS}

It is evident from the present study is that it is possible with gain enhancement through the proposed compact fractal metamaterial antenna. The broad impedance bandwidth and relatively small antenna size are attributed to the introduction of metamaterial as a ground plane. This proposed antenna is suitable for the frequency range 5.2 to $20 \mathrm{GHz}$.

Table 2. Gain and directivity under different frequencies

\begin{tabular}{|c|c|c|c|c|c|c|}
\hline Parameter & \multicolumn{6}{|c|}{ Proposed antenna } \\
\hline $\begin{array}{c}\text { Frequency } \\
\text { (GHz) }\end{array}$ & 5.2 & 10.5 & 12.5 & 16.2 & 17.5 & 20 \\
\hline $\begin{array}{c}\text { Gain } \\
\text { (dB) }\end{array}$ & 1.382 & 5.079 & 1.943 & 5.240 & 4.322 & 3.187 \\
\hline $\begin{array}{c}\text { Directivity } \\
\text { (dB) }\end{array}$ & 4.925 & 8.534 & 5.646 & 8.188 & 7.697 & 6.643 \\
\hline
\end{tabular}

\section{REFERENCES}

1. S.Tripathi, A. Mohan, and S. Yadav, A compact UWB Koch fractal antenna for UWB antenna Array applications, Wireless Personal Communications, 92(4)(2017) 1423-1442.

2. C.Vardadhan, J.K.Pakkathillam, M.Kanagasabai, R.Sivasamy, R.Natarajan and S.K.Palaniswamy, Triband antenna structures for RFID systems deploying fractal geometry, IEEE Antenna and Wireless Propagation Letters, 12 (2013) 437-440.

3. C.Puente, J.Romeu, R.Pous, X.Garcia, and F. Benitez, Fractal multiband antenna based on the Sierpinski gasket. Electronics Letters, 32(1)(1996)1-2.

4. A.Behera,S. Satrusallya and M.N. Mohanty (2016, April). Design of fractal antenna based on Koch-Sierpinski combination for UWB application. In 2016 International Conference on Communication and Signal Processing (ICCSP) (pp. 1701-1704). IEEE.

5. N.J.D. Dieu, and W. Zhou, Koch-based circular CPW fed dual UWB antenna, 2013 IEEE Conference on Microwave Technology and Computational Electromagnetics (ICMTCE), 200-203, Aug. 2013.

6. S.Singhal, P.Singh and A.K.Singh, Asymmetrically CPW-fed octagonal sierpinski UWB fractal antenna, Microwave and Optical Technology Letters, 58(7)(2016)1738-1745.

7. S.Tripathi, A.Mohan and S.Yadav, A compact octagonal-shaped fractal UWB antenna with Sierpinski fractal geometry, Microwave and Optical Technology Letters, 57(3) (2015) 570-574.

8. A.O. Kaka and M. Toycan, Modified hexagonal Sierpinski gasket-based antenna design with multiband and miniaturized characteristics for UWB wireless communication, Turkish Journal of Electrical Engineering and Computer Sciences, 24(2)(2016) 464-473.

9. G.Mishra and S. Sahu, Modified octahedron shaped antenna with parasitic loading plane having dual band notch characteristics for UWB applications, International Journal of $R F$ and Microwave Computer-Aided Engineering, 26(5)(2016) 426-434.

10. R.Kumar and N. Kushwaha , Design and investigation of sectoral circular disc monopole fractal antenna and its backscattering, Engineering Science and Technology, an International Journal, 20(1)(2017)18-27.

11. T.J.Cui, Electromagnetic metamaterials: Recent advances on the theory, experiments, and applications. 2009 International Conference on Microwave Technology and Computational Electromagnetics (ICMTCE 2009), pp. 12-13, 2009

12. D.Yayun, L.Wenwen ,Y. Xijun, Y.Chen and T. Houjun, Design of unit cell for metamaterials applied in a wireless power transfer system. In: IEEE PELS Workshop on Emerging Technologies: Wireless Power Transfer. 2017. pp. 143-147. DOI: 10.1109/WoW.2017.7959382

13. W.J. Krzysztofik and T.N.Cao, Metamaterials in Application to Improve Antenna Parameters, In Metamaterials and Metasurfaces. IntechOpen, 2018.

14. X.Han, H.J.Song, Z.Qing-Yi, and J. Da-Lin, Compact ultra-wideband microstrip antenna with metamaterials, Chinese Physics Letters, 29(11)(2012) 114102.

15. R. K. M. Lou, T. Aribi and C. Ghobadi, Improvement of Characteristics of Microstrip Antenna Using of Metamaterial Superstrate, International Conference on Communication Engineering, (2010), pp. 126- 129.

16. B. Garg, N. Agrawal, V. Sharma, A. Tomar and P. Dubey, Rectangular Microstrip Patch Antenna with Pentagonal Rings Shaped Metamaterial
Cover, International Conference on Communication System and Network Technologies IEEE, (2012), pp. 40-44

17. Ch.Manohar Kumar, NVSS Kumar Muvvala "Effect of Metamaterial on a Triangle Shaped Multi-Band Patch Antenna ", Journal of Emerging Technologies and Innovative Research, Vol 6, Issue 3 March 2019

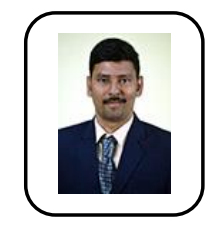

\section{AUTHORS PROFILE}

Mr.Ch.Manohar Kumar was born in 23-08-1987. He received his B.Tech (ECE) degree from St.Ann's College of Engineering And Technology Chirala,AP, India in 2008. He received his M.Tech from Andhra University Visakhapatnam,AP, in the field Radar And MicroWave engineering in 20103. Currently, he is a Research Scholar in Career Point University,Kota, Rajasthan,ECE. His research fields include Metamaterial Antennas ,Microstrip Antennas.

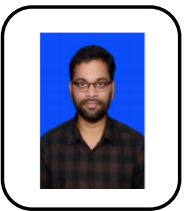

Dr. M N V S S Kumar was born in 08-08-1987 ,He received his B.Tech (ECE) degree from Andhra University Visakhapatnam,AP, India in 2008.He received his M.Tech from Andhra University Visakhapatnam, AP, in the field Radar And Micro Wave engineering in 2010.He completed his Ph.D degree in 2013 from Andhra University. His research fields include GPS Applications and Satellite communication. He published many Scoups and SCI Index Journals. 